ulty are more aware of their rights and limits. This is good news for the region, but it also means a major challenge for higher education institutions.

Note: While this article was in production, an important protest at Chilean universities was taking place. Several university buildings of at least I5 institutions have been occupied by female student activists, including the Pontifical Catholic University of Chile. Students are protesting against gender violence and for establishing protocols to report sexual harassment cases, to achieve a non-sexist education and to change the curriculum among other demands.

DOI: http://dx.doi.org/Io.6oI7/ihe.20I8.94.I0512

\section{Sexual Harassment at} African Higher Education Institutions

\section{Christine Dranzoa}

Christine Dranzoa is vice-chancellor at Muni University, Arua, and president of the Forum for African Women Educationalists (FAWE) in Uganda.E-mail: cdranzoa@yahoo.com.

$\mathrm{I}_{\mathrm{i} s}^{\mathrm{n}}$ n Africa, enrolling in higher education institutions (HEIs) is an aspiration of many young people and their families and represents an investment in their own socioeconomic progress. This is why university graduation ceremonies are celebrated with great pomp-the ceremonies anticipate significant long-term benefits. Higher education institutions are the power engine of Africa's progress. Additionally, issues of gender equality and diversity have gained momentum in the twenty-first century as it has become widely acknowledged that balanced economic and social progress is only possible with these tenets. Most governments in Africa have adopted and ratified policies such as the UN Universal Declaration of Human Rights and Freedoms (I948) and the African Union Gender Policy (2009), which mandate them to observe and practice gender equity and empower women in higher education institutions.

\section{The Vulnerability of Women in Higher Education in Africa}

In Egypt, 99 percent of women experience sexual harassment. In South Africa, three-quarters of women experience some form of abuse or sexual violence. In 2014 and 2015 ,
South African police recorded 53,000 rape cases annually. In the Democratic Republic of Congo and in Rwanda, many women report sexual violence by intimate partners. In Uganda, sexual harassment and gender-based violence against women, including abductions and murder, make the headlines on a weekly basis. Globally, 35 percent of women experience physical or sexual violence of all kinds. Women suffer derogatory comments and unsolicited sexual advances.

Students enrolling in higher education institutions in Africa have different backgrounds: some are freshly graduated from high school, some are mature-age entrants. Over 90 percent of the younger students are from poor families. Unlike higher education institutions, secondary schools and most homes are restrictive and heavily regulated when it comes to relations between the sexes. Traditionally, girls and boys are socialized differently, which has a negative im-

\section{In Egypt, 99 percent of women experi- ence sexual harassment. In South Afri- $\mathrm{ca}$, three-quarters of women experience some form of abuse or sexual violence.}

pact outside of these regulated spaces. Young female students entering HEIs are vulnerable, innocent, unexposed, and naïve, eager to explore their newly discovered freedom, sometimes ending up with unplanned pregnancies and dropping out altogether. The rampant, sexual manipulation of women, girls, and sometimes boys, happens within and outside the institutions. Most universities in Africa have gender policies and policies against sexual harassment, but several factors contribute to sexual harassment and genderbased violence. University hostels, where disadvantaged female and male students stay, are often cheap and unregulated, serving as the first location for sexual harassment because they attract sexual predators. Other contributing factors include financial need, the imperative to get good grades to open doors on a scarce labor market, graduate unemployment, and peer pressure. Monitoring systems are often in place, but are weakened by unprofessional administration. A strong patriarchal tradition, often aggravated by sheer misogynistic behavior, undermine female staff and students systematically, contributing to denying them advancement and ruining their academic careers. Some perpetrators of gender-based violence are persons of responsibility and influence on the students, such as faculty, course coordinators, and examination officers. Finally, substance abuse contributes to a culture that is unconducive to respect 
between the sexes.

Strategic Advancement of Gender Equity and Equality Strategic advancement toward gender equality and a violence-free society should include sensitizing and empowering men and boys on gender issues. Dedicated professional counselors, psychologists, deans of students, and wardens should work in an organized and structured manner with student peers, executive management, and faculties to offer counseling, sensitization, and open discussions on what triggers sexual harassment and gender-based violence. Coordinating both academic and extracurricular activities such as nature clubs, sports, and games gives opportunities for feedback and keeps young people busy and healthy. Student counselling on social issues, responsible residential life at universities, prevention against diseases such as HIV/AIDS and hepatitis combined with a strict institutional culture and gender policy are practical ways to build inclusive, respectful, and diverse academic communities. Consistently communicating, advising, and sensitizing students is crucial. Reversing a nefarious culture requires bold institutional leadership dealing decisively with cases of sexual misconduct, coupled with a rigorous selection of professional staff.

\section{CONCLUSION}

Sexual harassment and gender-based violence in higher education are signs of institutional failure. Indeed, victims may see their academic careers stunted or destroyed. The vicious cycle of poverty and moral decadence is perpetuated. Endemic gender-based violence and sexual harassment undermine the attainment of the Sustainable Development Goals in the African context.

DOI: http://dx.doi.org/I0.60I7/ihe.20I8.94.10513

\section{The \#MeToo Movement as a Global Learning Moment}

\section{Joanna Regulska}

Joanna Regulska is professor of gender, sexuality, and women's studies and vice-provost and associate chancellor, Global Affairs, University of California, Davis, US. E-mail: jregulska@ucdavis.edu.

$\mathrm{M}$ ost women around the world have experienced sexual harassment, assault, and violence, or have at times been pushed into a zone where they knew it did not feel right. They have experienced the "same" moment, and yet for each of them it has been a different moment. For some it was an "aha" moment; for some the pain, emotional and physical, may have been unbearable, lasting for days, months, or years. For others still, this moment had to be deeply buried. It could not be spoken about because of its cultural and political context; it was identifiable but stripped of the power that comes from naming. This moment of articulation and recognition may be shaped by women's age, sexual orientation, trans status, race, ethnicity, socioeconomic position, religion, by broader cultural practices, and by a great many other formative experiences, present and past.

This essay places the \#MeToo movement within the context of global learning. Given the global nature of sexual harassment, assault, and violence against women, but also given the common dismissal of such women's experiences, what responsibilities do we have as international educators? How should we place this particular moment within a larger and broader effort in order to provide our students with global and international understanding? How can we harness this global movement in ways that will advance intercultural and intracultural awareness? How can we engage our students, faculty, and staff members in exploring these spaces of lived experiences that are so full of emotions, fear, and pain, but at the same time are embedded within diverse cultural practices in ways that may well give rise to misunderstandings?

\section{The Complexities of the Moment}

This is a very powerful and yet a very complicated moment. It is powerful because it resonates with women around the world and therefore presents an opportunity to have conversations in different parts of the world and with people representing different cultural experiences and perspectives: this is an opportunity for global learning at home and abroad. As I travel to different countries, I also hear denial, dismissal, and open criticism. \#MeToo does not resonate with everyone; for many, it is seen as a matter of a privilege that women living under extreme poverty or in war-torn countries cannot afford.

This is an exciting moment because women are defining what harassment, violence, and assault mean for them. How have these lived experiences affected their own understandings of their bodies or of their positions within the larger society? But it is also a complicated moment because it requires from us a recognition that it is formed by local cultural context, political climate, powerful institutions, class, racial and ethnic privileges, heteronormativity, and many other pressures, exercised by networks of power and domination. 